\title{
UMA ANÁLISE DA MULTIMIDIALIDADE E RECURSOS INTERATIVOS EM UM AMBIENTE VIRTUAL DE APRENDIZAGEM
}

\section{AN ANALYSIS OF A VIRTUAL LEARNING ENVIRONMENT MULIMEDIALITY AND INTERACTIVE RESOURCES}

\author{
Flavia Lumi Matuzawa ${ }^{1}$, M.Eng. \\ Berenice Santos Gonçalves ${ }^{2}$, Dra. \\ (1) Universidade do Sul de Santa Catarina / Unisul \\ e-mail: fla.matuzawa@gmail.com \\ (2) Universidade Federal de Santa Catarina / UFSC \\ e-mail:berenice@cce.ufsc.br
}

Ambiente virtual de aprendizagem, novas mídias, multimidialidade

Ambiente virtual de aprendizagem é essencial ao processo ensino-aprendizagem na Educação a Distância. Neste artigo, debruça-se um estudo sobre a identificação e uso de mídias em uma disciplina a distância, tecendo um paralelo com os referenciais do webjornalismo. Constata-se baixa interação dos estudantes no uso das mídias disponíveis e desafios técnicos e instrucionais para ofertar conteúdos que promovam efetiva aprendizagem.

\section{Virtual learning environment, new media, multimediality}

A virtual learning environment is essential to the teaching and learning process in Distance Education. This article focuses on the use and identification of media based on the offer of a distance course, drawing parallels between them and webjournalism references. Low student interaction with the media available as well as technical and instructional challenges to offer contents that promote effective learning were observed.

\section{Introdução}

A trajetória da Educação a Distância (EAD) remonta às primeiras experiências realizadas pelo ensino por correspondência, passando por conceitos envolvendo distância transacional, ferramentas online de comunicação, processo de produção de materiais, design instrucional e uso de ambientes virtuais de aprendizagem. Os relatos práticos datam por reconhecidas universidades como Fernuniversität (Alemanha) e Open University (Inglaterra) em meados de 1970 (NUNES, 2009; PETERS, 2001; PETERS, 2003). Desde então, pesquisadores de variadas instituições de ensino estudam possibilidades de interação entre os pares, desenvolvem mecanismos de produção e acesso a conteúdos didáticos e estudam 


\section{$16^{\circ}$ \\ ERGODESIGN USIHC CINAHPA}

$16^{\circ}$ Ergodesign - Congresso Internacional de Ergonomia e Usabilidade de Interfaces Humano Tecnológica: Produto, Informações Ambientes Construídos e Transporte

$16^{\circ}$ USIHC - Congresso Internacional de Ergonomia e Usabilidade de Interfaces Humano Computador

CINAHPA | 2017 - Congresso Internacional de Ambientes Hipermídia para Aprendizagem. formas do uso intensivo de tecnologias da informação e comunicação (TIC) no processo educacional. Nessa caminhada, o uso de tecnologias para promover e viabilizar o processo ensino aprendizagem cada vez mais se mostra como um desafio para a EAD. No contexto online, destacam-se os ambientes virtuais de aprendizagem (AVA) como uma metáfora de sala de aula que buscar simular o acesso a conteúdos didáticos e orientação pedagógica além de promover a interação entre pares (MONEREO \& POZO, 2010; ARAUJO Jr \& MARQUESI, 2009; Harasim et al, 2005; PETERS, 2003).

Ao apresentar, anualmente, seis tendências-chave, seis desafios significativos e seis importantes desenvolvimentos para o uso de tecnologia em educação, o conhecido relatório NMC Horizon Report ${ }^{1}$ tem trazido direcionamentos importantes para a pesquisa em educação de modo geral.

Figura 1 - Visão geral dos tópicos principais abordados no relatório NMC de 2016

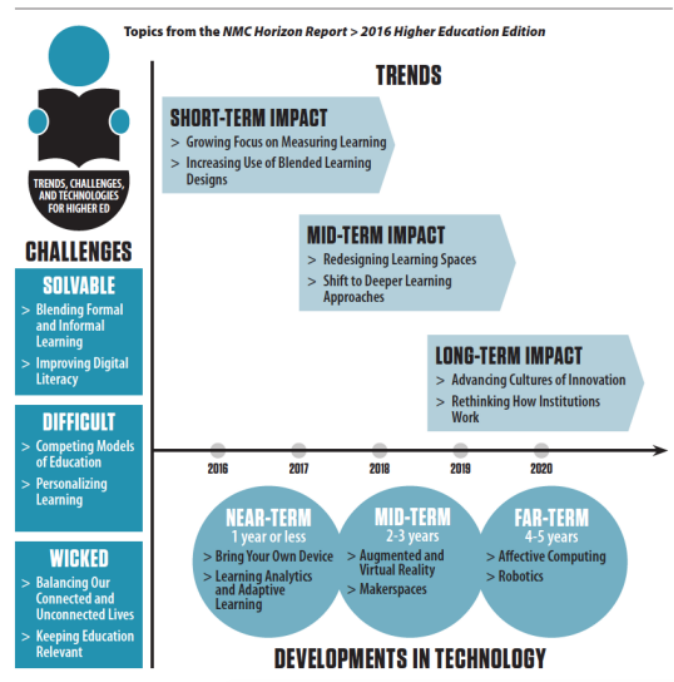

Fonte: JOHNSON et al. (2016, p.2)

\footnotetext{
${ }^{1}$ Trata-se de um trabalho de acesso livre disponibilizado para consulta cuja primeira edição para Educação Superior foi lançada em 2004 e, por ter sido bem recebido pelos formuladores de políticas, profissionais e líderes de pensamento, tornou-se uma publicação anual. De modo geral, ela apresenta e analisa as fortes tendências e possíveis impactos no contexto educacional diante o uso das tecnologias.
}

Em específico, na edição de 2016 pode-se perceber que os AVA - embora não sendo o foco direto do relatório - precisam estar adequados para acompanhar a tecnologia de um futuro próximo. O relatório demanda um olhar cuidadoso em desenvolvimento de metodologias e tecnologias para trabalhar em educação e torna-se evidente tanto na concepção de espaços de aprendizagem como em realidade virtual, computação afetiva, robótica e reflexos que a tecnologia móvel trará ao contexto educacional. A partir da Figura 1 pode-se perceber os desafios organizados em impactos de curto, médio e longo espaço de tempo. Em especial, na base da figura constam os desenvolvimentos em tecnologia necessários para atender aos desafios acima mencionados.

O presente estudo fica sensível aos desenvolvimentos em tecnologia relacionados ao curto espaço de tempo estimado entre um ano ou menos, especificamente sobre como acompanhar o aprendizado do estudante por meio das interações e atividades online. Estas ações podem ser implementadas em espaços como o AVA que forneçam ferramentas e possibilidades automatizadas, por exemplo. Este artigo parte da afirmação apontada no relatório onde as tecnologias de aprendizagem adaptativa aplicam uma análise na aprendizagem através de softwares e se adaptam às necessidades individuais dos estudantes (JOHNSON et al., 2016). Tendo esta realidade como algo a ser conquistado, parte-se de um olhar aos AVA acerca do que se tem à disposição para perceber como aconteceria esta aprendizagem, como estão disponibilizando as mídias e quais potenciais e carências encontram-se disponíveis.

Em paralelo aos indicadores do relatório NMC de 2016, Zawacki-Richter e Olaf (2014) trazem em sua obra uma possível agenda de pesquisa indicando áreas importantes de desafios em EAD. Neste trabalho, há menção ao estudo Delphi* que desenvolveu um quadro teórico de tópicos de pesquisa que ajudariam a organizar o conhecimento na área e identificar lacunas e oportunidades de pesquisa. Este quadro está organizado por três níveis: o macro, meso e micro.
Realização:

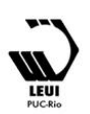




\section{$16^{\circ}$ \\ ERGODESIGN USIHC CINAHPA}

$16^{\circ}$ Ergodesign - Congresso Internacional de Ergonomia e Usabilidade de Interfaces Humano Tecnológica: Produto, Informações Ambientes Construídos e Transporte

$16^{\circ}$ USIHC - Congresso Internacional de Ergonomia e Usabilidade de Interfaces Humano Computador

CINAHPA | 2017 - Congresso Internacional de Ambientes Hipermídia para Aprendizagem.
O nível Macro abrange teorias e sistemas de educação a distância; o nível Meso abrange gestão, organização e tecnologia e por fim, o nível Micro abrange ensino e aprendizagem na educação a distância (ZAWACKI-RICHTER E OLAF, 2014, p. 4). Mais uma vez, os AVA não são mencionados diretamente, mas percebe-se, por exemplo, no nível micro, a necessidade de estudos em torno de temáticas como o cuidado com o design do material didático, práticas de avaliação na EAD, desenvolvimento de comunidades online, considerações em design instrucional que incentivem a articulação, interação, reflexão e colaboração online, alfabetização online dentre outras temáticas igualmente importantes. Esses estudos implicam diretamente, mas não necessariamente, em um ambiente virtual para que o processo ensino-aprendizagem possa acontecer e, sendo assim, acredita-se que os AVA podem ser um ambiente para isso.

Embora as mídias e AVA sejam temáticas abordadas pela literatura, isto é, mesmo não sendo temáticas recentes, considera-se o uso das mídias nestes ambientes virtuais um desafio ainda real ao processo de ensino-aprendizagem visto que, apesar da forte tendência no uso de dispositivos móveis (e aqui entra o desafio do chamado Bring Your Own Device ${ }^{2}$ ) percebe-se na prática a necessidade de explorar o potencial das mídias nesses espaços junto aos estudantes.

Mas, antes de chegar à tecnologia móvel, ponderase em que medida os AVAs acessados a partir de dispositivos tradicionais assimilaram o uso das mídias de maneira a promover o devido envolvimento do público alvo e/ou promovendo a interação desejada aos usuários?

Illera (2010) levanta uma questão oportuna no contexto educacional ao afirmar que usa mídias não somente pelo seu caráter multimidiático, mas

\footnotetext{
${ }^{2}$ Bring Your Own Device é um termo empregado para a prática das pessoas levarem seus próprios equipamentos como notebooks, tablets, smartphones ou qualquer outro dispositivo móvel para seu local de aprendizagem ou ambiente de trabalho. É uma frente apresentada como desafio pelo relatório NMC 2016.
}

também pelo uso específico de imagens, som e imagem em movimento. Sua inquietação passa pela forma como essas mídias se compõem no interior de uma única tela que as apresenta. E é neste sentido que o artigo busca abordar os ambientes virtuais ao analisar como se caracteriza o uso das novas mídias ${ }^{3}$ no contexto educacional.

Considerando o contexto educacional e a entrega de conteúdos didáticos em ambientes virtuais, este artigo apresenta a análise de um ambiente de aprendizagem específico para orientar a observação prática. Foi utilizada uma sala virtual de disciplina para o ensino de animação para perceber como se caracteriza o uso das mídias neste ambiente de acordo com o referencial teórico, não alcançando a pretensão de uma análise de cunho pedagógico neste momento. A análise das mídias se desenvolveu segundo a perspectiva de Manovich (2001), e de autores do web jornalismo, a saber, Canavilhas (2014) e Salaverría (2014) quanto à classificação das mídias e de características de ambientes digitais.

\section{Fundamentação}

Apesar de não se configurarem como um assunto novo no contexto da EAD, de acordo com o Censo EAD. BR (2015, p.10), os ambientes virtuais de aprendizagem (AVA) têm sido a ferramenta mais utilizada tanto para o compartilhamento de conteúdos didáticos quanto para a comunicação com os estudantes.

Independente da disposição dos elementos instrucionais, de comunicação e de interação em um ambiente virtual, o que já era um desafio para as estratégias pedagógicas no AVA acessado por computadores desktop e notebooks, parece ampliar-se diante as possibilidades técnicas de acesso pelas tecnologias móveis. As características próprias dos dispositivos móveis podem sinalizar maneiras diferentes de apresentar e interagir com os conteúdos. O ponto chave para o ambiente virtual é que, independente do dispositivo de

${ }^{3}$ Manovich (2001) define as novas mídias como objetos culturais que usam a tecnologia computacional digital para distribuição e exposição de dados e informações.
Realização:

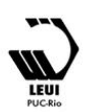




\section{$16^{\circ}$ \\ ERGODESIGN USIHC CINAHPA}

$16^{\circ}$ Ergodesign - Congresso Internacional de Ergonomia e Usabilidade de Interfaces Humano Tecnológica: Produto, Informações Ambientes Construídos e Transporte

$16^{\circ}$ USIHC - Congresso Internacional de Ergonomia e Usabilidade de Interfaces Humano Computador

CINAHPA | 2017 - Congresso Internacional de Ambientes Hipermídia para Aprendizagem. acesso, os conteúdos didáticos estarão acessíveis a todo usuário devido à possibilidade do formato digital dos conteúdos. Portanto as mídias digitais são elementos fundamentais destes espaços.

Neste artigo, atribui-se o termo mídias digitais a partir do contexto das novas mídias caracterizado por Manovich (2001), ou seja, são objetos culturais que usam a tecnologia computacional digital para distribuição e exposição de dados e informações. Manovich (2001) destaca em "The Language of New Media" algumas qualidades das mídias digitais que trazem elementos importantes a este estudo: a possibilidade de representação numérica, a modularidade, a automação, variabilidade e transcodificação.

Ao comentar sobre a obra de Manovich, Martino (2015) afirma que a característica da representação numérica parte do pressuposto de que todos os elementos das novas mídias são parte de um código digital, isto é, uma representação numérica baseada em uma sequencia de 0 s e $1 \mathrm{~s}$. Esta característica possibilita a intervenção na edição de um conteúdo devido à sua natureza manipulável de 0 e 1, isto é a mídia torna-se programável. Já a modularidade considera as novas mídias compostas por partes relativamente separadas, ou separáveis entre si que podem assumir significados diferentes conforme o contexto em que são utilizadas. Essa característica vai possibilitar uma capacidade combinatória de elementos onde, cada um deles torna-se um módulo no documento, além disso, estes elementos mantém suas próprias características podendo ser editados isoladamente.

A modularidade permite uma manutenção facilitada diante a necessidade de atualização de conteúdos, por exemplo. Ao contrário da modularidade que permite a combinação de elementos diferentes a um conteúdo inicial, a variabilidade vai trabalhar sobre o mesmo conteúdo por meio de versões a partir dele mesmo, possibilitando criar reproduções mais ou menos semelhantes de um mesmo objeto, variando em pequenos detalhes.

A automação permite a personalização dos conteúdos visto que é como se fosse um resultado da combinação numérica binária e modularidade das estruturas ao permitir que a nova mídia seja executada automaticamente pela máquina a partir de suas próprias decisões.

Por fim, Martino (2015) apresenta a transcodificação como a combinação da influência de duas visões diferentes: "lado cultural" (elementos reconhecíveis por seres humanos imagens, letras, sons, figuras, interfaces baseadas em elementos reais) e "lado computacional" (lógica matemática do computador). A influência de ambas visões acabam por vezes ultrapassando as barreiras de qualquer tela, alterando também a cultura humana. Aqui parte-se para um olhar sobre a influência da interface, assunto relevante ao contexto educacional, porém fora do escopo deste estudo.

Se considerarmos estas características que abordam diretamente as facilidades de representação da informação ao se trabalhar com o potencial digital, temos a possibilidade de olharmos para o ambiente virtual como um espaço para atender não somente a oferta de conteúdos em diversos formatos (tanto sob o ponto de vista pedagógico como técnico), mas também novas possibilidades de interação conforme a tecnologia permite, como é o caso das possibilidades que se abrem a partir da plasticidade e tactibilidade, por exemplo. Estas características segundo Canavilhas (2014, p.6) remetem ao valor do touchscreen como uma "evolução da interatividade seletiva" uma vez que permite ao usuário do dispositivo interagir diretamente com o conteúdo. A plasticidade é entendida pela adaptação do dispositivo ao seu usuário, marcada então pelos "serviços" oferecidos por funções do acelerômetro, giroscópio e GPS dos dispositivos móveis.

Ao considerar as possibilidades tecnológicas, Canavilhas (2014) apresenta sete características observáveis no contexto dos produtos jornalísticos na web que podem servir como um possível referencial para observar aos ambientes virtuais de aprendizagem. Memória, multimidialidade, interatividade, personalização, hipertextualidade, instantaneidade e ubiquidade são as características apresentadas na obra de Canavilhas (2014) de
Realização:

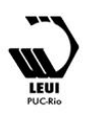




\section{$16^{\circ}$ \\ ERGODESIGN USIHC CINAHPA}

onde, especificamente, este artigo tratará da multimidialidade.

Salaverría (2014) entende multimedialidade como a combinação de linguagens e o autor considera a multimídia como sendo a combinação de pelo menos dois elementos de mídia variando de acordo com a intenção e possibilidades técnicas definição esta a ser base para o trabalho presente: texto, fotografia, gráficos, iconografia, ilustrações estáticas, vídeo, animação digital, discurso oral, música, efeitos sonoros e vibração.

(SALAVERRÍA, 2014, p. 33)

Outro ponto igualmente importante na obra de Canavilhas (2014) está na abordagem das gerações de produtos jornalísticos na web. Sua referência inicial está na imprensa escrita que caracteriza a primeira geração marcada por uma transposição de conteúdos previamente apresentados no papel. A segunda geração passa pelo potencial da hipertextualidade ao enriquecer as temáticas tratadas nas notícias e, por fim, a terceira geração apresentando a possibilidade de personalização modelo que o jornalismo rompe com a referência ao modelo tradicional de fazer notícia: a web passa a ser utilizada em toda sua potencialidade no uso de texto, imagem, som e imagem em movimento. Ao refletir sobre os AVA atualmente utilizados, percebe-se que estas gerações também aludem à forma com que as mídias são e podem ser empregadas no processo de ensino e aprendizagem.

Canavilhas (2014) e Salaverría (2014) contribuem a esta temática ao tratarem de características que, além de não se confrontarem com Manovich (2001), possibilitam uma leitura complementar entre si. Embora sob a perspectiva do jornalismo, é fato que as mídias nos ambientes digitais cumprem objetivos de comunicar informação a um público específico. É diante tais contribuições que se apropria destes conceitos para um olhar visto na perspectiva da educação.

Além das mídias e características dos ambientes virtuais, cabe destacar as possibilidades de agrupar as mídias no AVA - tendo em vista a intencionalidade pedagógica das informações ali $16^{\circ}$ Ergodesign - Congresso Internacional de Ergonomia e Usabilidade de Interfaces Humano Tecnológica: Produto, Informações Ambientes Construídos e Transporte

$16^{\circ}$ USIHC - Congresso Internacional de Ergonomia e Usabilidade de Interfaces Humano Computador

CINAHPA | 2017 - Congresso Internacional de Ambientes Hipermídia para Aprendizagem. presentes. Salaverría (2014), ao tratar do contexto jornalístico, menciona a possibilidade na articulação de elementos de mídia no ambiente digital por justaposição, coordenação e subordinação. Fazendo um paralelo às regras sintáticas na organização das palavras na composição de uma oração, o autor entende a multimidialidade por justaposição como a forma mais básica de organização, uma vez que os elementos se unem segundo um critério informativo. Aqui, os elementos apenas se relacionam no tempo e no espaço, limitando assim a potencialidade multimídia. A multimidialidade por subordinação segue a lógica de haver uma hierarquia entre os elementos. Existem os elementos de acesso inicial que se constituem no elo principal seguido de outros elementos subsequentes. A terceira possibilidade seria a multimidialidade por coordenação: uma forma mais complexa de se organizar os elementos multimídia uma vez que procura convergi-los para um único discurso. Aqui existe uma combinação de textos, sons, fotografias, vídeos (ou outros elementos) em simultâneo o que pode se configurar em um desafio na sua elaboração coordenada de todos os elementos.

Entender a combinação das mídias nesta perspectiva pode trazer um mapeamento interessante de um AVA, uma vez que permitirá perceber quais elementos estão sendo utilizados ou não. Esse é um exercício de análise e reflexão proposto para a composição de uma sala virtual na área de animação ofertada na modalidade a distância.

\section{Análise de um Ambiente Virtual de Aprendizagem}

Para este estudo foram analisadas as mídias utilizadas na sala virtual de uma disciplina ofertada na modalidade a distância, visando o ensino de animação. A disciplina é oferecida por uma instituição de ensino superior e conta com plataforma de aprendizagem própria. Foi realizada uma observação das mídias empregadas nesta sala virtual e uma análise dos acessos de estudantes pela internet das quatro últimas turmas ofertadas nos semestres de 2015 e 2016 . O objetivo foi o de 


\section{$16^{\circ}$ \\ ERGODESIGN USIHC CINAHPA}

perceber as mídias segundo o referencial teórico abordado anteriormente e buscar nos dados de acesso alguma confirmação segundo as análises feitas.

O processo de observação ocorreu a partir das seguintes etapas: (a) análise do relatório de acessos realizados pelos alunos ao ambiente virtual emitido em 20/01/2017correspondente aos meses de março a novembro de 2015 e 2016; (b) análise de acessos aos tópicos de estudo por meio do relatório emitido pela sala virtual de cada turma; (c) observação do uso das ferramentas em casa sala virtual; (d) elaboração de planilhas de apoio para análise e geração de gráficos; (e) interpretação dos resultados.

Para as quatro turmas analisadas soma-se um total de 302 estudantes. Além da observação direta do ambiente virtual, buscou-se compreender os acessos à plataforma por meio de dados quantitativos. A partir das características apresentadas, buscou-se uma reflexão acerca do uso das mídias neste espaço considerando para isso, a abordagem de Canavilhas (2014) para caracterizar as mídias do AVA e de Salaverría para a análise de distribuição das mesmas.

Em uma análise inicial, distribuiu-se as possíveis mídias de acordo com Canavilhas e Salaverría (2014) e para cada uma, fez-se uma análise da aplicação das mesmas nos espaços de interação do AVA. O quadro 1 ilustra, para cada ferramenta, $16^{\circ}$ Ergodesign - Congresso Internacional de Ergonomia e Usabilidade de Interfaces Humano Tecnológica: Produto, Informações Ambientes Construídos e Transporte

$16^{\circ}$ USIHC - Congresso Internacional de Ergonomia e Usabilidade de Interfaces Humano Computador

CINAHPA | 2017 - Congresso Internacional de Ambientes Hipermídia para Aprendizagem. uma coluna da possibilidade de ocorrência da mídia (Poss.) e a utilização real (Real) da mesma.

Observa-se que, embora exista a possibilidade de uso de variadas mídias nestes espaços do AVA, há pouca utilização das possibilidades nestas salas virtuais, o que acaba por conferir um ambiente virtual baseado principalmente em informações textuais com uso de hiperlinks para informações externas ao conteúdo do AVA possibilitando então, e somente então, acesso a vídeos, animações ou outro recurso para além do texto.

Infelizmente ao consultar dados de acesso, a plataforma não permite perceber qual mídia foi acessada pelo estudante, senão o espaço geral denominado "Tópicos de estudo". Cada disciplina apresenta um número próprio de tópicos para trabalhar os conteúdos específicos. No caso da disciplina estudada, tem-se um total de 7 tópicos. Do total de 302 estudantes percebe-se algumas interações a algumas ferramentas e espaços dentro do AVA. Embora dentro de cada tópico existam mídias diferenciadas também não é possível perceber pelo relatório de acesso quando uma animação ou vídeo foi acionado pelo estudante. A informação extraída do relatório apenas indica que houve acesso ao tópico desejado. Com isso, sabese apenas se o estudante clicou sobre um tópico de estudo - dado este que não garante a realização da leitura, atividades propostas, nem a visualização de mídias, caso existam.

Quadro 1 - Identificação das mídias usadas no AVA

\begin{tabular}{|c|c|c|c|c|c|c|c|c|c|c|c|c|c|c|c|c|}
\hline \multicolumn{17}{|c|}{ Características dos contextos digitais (CANAVILHAS, 2014): das 7 características a observação, escolheu-se a Multimedialidade } \\
\hline \multirow{3}{*}{$\begin{array}{c}\begin{array}{c}\text { Elementos da } \\
\text { linguagem } \\
\text { multimídia }\end{array} \\
\text { (SALAVERRÍA, 2014) }\end{array}$} & \multicolumn{16}{|c|}{ Mídias do AVA: sala virtual do ensino em animação } \\
\hline & \multicolumn{2}{|c|}{ MURAL } & \multicolumn{2}{|c|}{$\begin{array}{l}\text { MIDIATECA e } \\
\text { EXPOSICAO }\end{array}$} & \multicolumn{2}{|c|}{ FORUM } & \multicolumn{2}{|c|}{ CHAT } & \multicolumn{2}{|c|}{ WEBCONF } & \multicolumn{2}{|c|}{$\begin{array}{l}\text { TUTOR e } \\
\text { PROFESSOR }\end{array}$} & \multicolumn{2}{|c|}{ AVALIAÇÃO } & \multicolumn{2}{|c|}{$\begin{array}{l}\text { TOPICOS de } \\
\text { ESTUDO }\end{array}$} \\
\hline & Poss. & Real & Poss. & Real & Poss. & Real & Poss. & Real & Poss. & Real & Poss. & Real & Poss. & Real & Poss. & Real \\
\hline Texto & $x$ & $x$ & $x$ & $x$ & $x$ & - & $x$ & - & $x$ & - & $x$ & $x$ & $x$ & $x$ & $x$ & $x$ \\
\hline Fotografia & $x$ & - & - & - & $x$ & - & - & - & $x$ & - & $x$ & - & - & - & $x$ & - \\
\hline $\begin{array}{l}\text { Gráficos, iconografia } \\
\text { e il. estáticas }\end{array}$ & $\mathrm{x}$ & $\mathrm{x}$ & - & - & $x$ & - & $x$ & - & $\mathrm{x}$ & - & $x$ & - & - & - & $x$ & - \\
\hline Vídeo & $x$ & - & - & - & - & - & - & - & $x$ & - & $x$ & - & $x$ & - & $x$ & - \\
\hline Animação digital & $x$ & - & - & - & - & - & - & - & - & - & - & - & - & - & $x$ & - \\
\hline Discurso oral & $x$ & - & - & - & $x$ & - & - & - & $x$ & - & $x$ & - & $x$ & - & $x$ & - \\
\hline $\begin{array}{l}\text { Música e efeitos } \\
\text { sonoros }\end{array}$ & $x$ & - & - & - & $x$ & - & - & - & $x$ & - & $x$ & - & $x$ & - & $x$ & - \\
\hline Vibração & - & - & - & - & - & - & - & - & - & - & - & - & - & - & - & - \\
\hline
\end{tabular}

Fonte: elaborado pelas autoras (2017)

Realização:

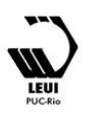

UNIVERSIDADE FEDERAL DE SANTA CATARINA
INSTITUTO FEDERAL

Santa Catarina Câmpus Palhoça Bilíngue 


\section{$16^{\circ}$ \\ ERGODESIGN USIHC CINAHPA}

Essa limitação já é um indício da dificuldade de viabilizar no AVA, o acompanhamento da aprendizagem do estudante por meio de interações no ambiente virtual. Sem saber por onde o estudante passou, se teve êxito ou não, fica difícil de se pensar em aprendizagem adaptativa em um contexto em EAD.

Figura 2 - Acessos aos Tópicos de Estudo no AVA

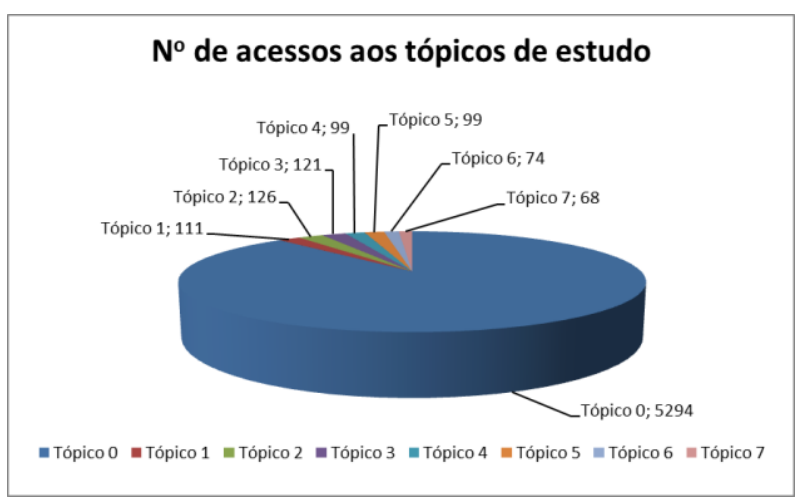

Fonte: elaborado pelas autoras (2017)

Com relação à ocorrência de multimidialidade observa-se poucas e simples combinações de texto e imagem, caracterizando-se em uma multimidialidade por justaposição, como classifica Salaverría (2014), constituindo assim a forma mais básica de organização da informação. Foi constatada na sala virtual apenas uma orientação aos estudantes participarem de um processo avaliativo no sistema acadêmico da instituição, apresentando neste caso uma imagem com passo a passo para efetivar a ação.

Embora o uso de vídeos e animações possa atrair a atenção e envolvimento do estudante, seria oportuna uma observação mais aprofundada, visto que, diante o maior índice dos acessos está concentrado no Tópico 0 ("Roteiro de estudos") que apresenta o roteiro geral de todos os elementos instrucionais ao longo dos tópicos de estudo. Como neste tópico apresenta-se todas as informações de maneira textuais, supõe-se que os estudantes buscam por uma visualização geral dos conteúdos apresentados na disciplina não indo necessariamente explorá-los a fundo, tópico por tópico. $16^{\circ}$ Ergodesign - Congresso Internacional de Ergonomia e Usabilidade de Interfaces Humano Tecnológica: Produto, Informações Ambientes Construídos e Transporte

$16^{\circ}$ USIHC - Congresso Internacional de Ergonomia e Usabilidade de Interfaces Humano Computador

CINAHPA | 2017 - Congresso Internacional de Ambientes Hipermídia para Aprendizagem.
Figura 3 - Visualização do Roteiro de Estudos (Tópico 0) do AVA

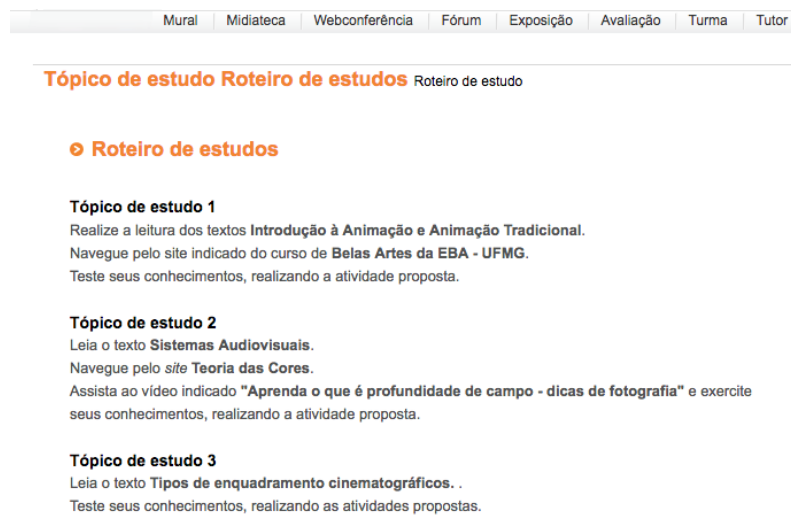

Fonte: Ambiente Virtual de Aprendizagem da Instituição (2017)

Os vídeos indicados para os estudos, com exceção dos produzidos pela equipe interna da instituição, geralmente são conteúdos de terceiros e, por isso, constituem-se inseridos por meio de links que apontam para sites externos. Já as animações produzidas pela equipe técnica da instituição são disponibilizadas de forma mais visual. Mesmo com baixa interatividade por parte do estudante, a animação já demarca a presença desta nova mídia.

Figura 4 - Exemplo de animação no AVA

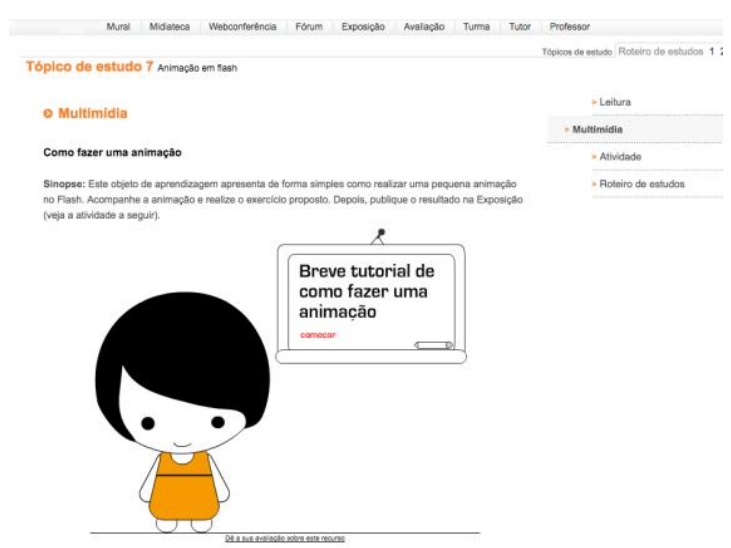

Fonte: Ambiente Virtual de Aprendizagem da Instituição (2017) 


\section{$16^{\circ}$ \\ ERGODESIGN USIHC CINAHPA}

Partindo para uma observação mais ampla de características do ambiente virtual, encontra-se espaço para que as mídias sejam aprofundadas e desenvolvidas. A representação numérica possibilitando ao ambiente ser programável poderia ser trabalhada com maior foco uma vez que os recursos programados praticamente inexistem. Certamente essa possibilidade enriqueceria o ambiente com atividades simuladas e automatizadas. O AVA apresenta espaços onde conteúdos são distribuídos e, em especial, o "Tópicos de estudo" permite atender tanto a modularidade como a variabilidade, uma vez que é possível aproveitar conteúdos de outras salas virtuais e adaptá-las com conteúdos específicos que forem necessários. A transcodificação fica pouco explorada uma vez que a estrutura do ambiente é fixa e o modelo instrucional é préformatado - o que impossibilita novas formas de apresentação dos conteúdos.

O uso de vídeo e áudio são possibilidades recentes no ambiente virtual em estudo (atualmente em etapa piloto) que foram implementadas para que professores e estudantes possam registrar pequenos trechos em áudio ou vídeo para situações de esclarecer dúvidas, por exemplo. Estas possibilidades estão disponíveis em ferramentas como Mural, Professor, Fórum, entretanto, na sala da disciplina analisada, a ferramenta ainda não está disponível para uso; o que impossibilitou a observação do uso em efetivo.

Sobre o vídeo é possível considerar a ferramenta de webconferência que, em um primeiro momento caracteriza-se por uma transmissão em tempo real com participação ativa de professor e estudantes e, em momento posterior, fica disponível como um vídeo para que os estudantes possam assistir offline. $16^{\circ}$ Ergodesign - Congresso Internacional de Ergonomia e Usabilidade de Interfaces Humano Tecnológica: Produto, Informações Ambientes Construídos e Transporte

$16^{\circ}$ USIHC - Congresso Internacional de Ergonomia e Usabilidade de Interfaces Humano Computador

CINAHPA | 2017 - Congresso Internacional de Ambientes Hipermídia para Aprendizagem.
Figura 5 - Exemplo de transmissão de webconferência no AVA

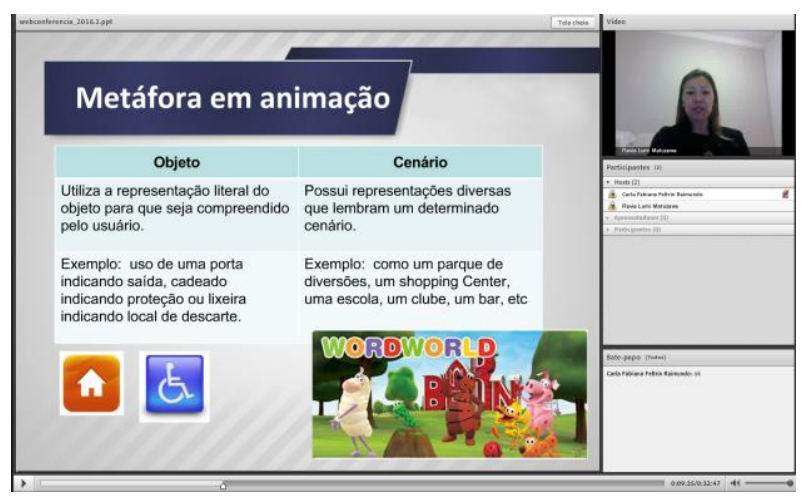

Fonte: organizado pelas autoras (2017)

\section{Conclusão}

Conforme observado nesta análise do AVA percebe-se que há uma caminhada para a apropriação do uso das mídias por parte dos designers instrucionais, designers visuais, professores e estudantes. Com relação às gerações apontadas por Canavilhas (2014) pode-se dizer que o AVA analisado enquadra-se ainda na segunda geração, uma vez que prioriza a transposição de conteúdos (do papel para o digital) e faz uso de hipertextualidades. Alcançar a terceira geração agregará valor ao processo ensino-aprendizagem além de fazer uso cada vez mais apropriado das novas mídias a favor do objetivo planejado, neste caso, o objetivo educacional. Neste caso, a estrutura do AVA teria de ser revista para comportar elementos mais programáveis, por exemplo.

O desafio se estende também para atender aos pontos de médio e longo prazo apontados pelo relatório NMC, de 2016. Além das possibilidades tecnológicas, o desafio também fala de apropriação da tecnologia, formação adequada para o devido uso e equipe técnica qualificada para desenvolvimento computacional. Existe uma necessidade em termos de possibilidade de produção de materiais instrucionais por meios diferentes do texto escrito. Imagens, vídeos e animação podem acrescentar valor e viabilizar
Realização:

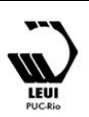




\section{$16^{\circ}$ \\ ERGODESIGN USIHC CINAHPA}

$16^{\circ}$ Ergodesign - Congresso Internacional de Ergonomia e Usabilidade de Interfaces Humano Tecnológica: Produto, Informações Ambientes Construídos e Transporte

$16^{\circ}$ USIHC - Congresso Internacional de Ergonomia e Usabilidade de Interfaces Humano Computador

CINAHPA | 2017 - Congresso Internacional de Ambientes Hipermídia para Aprendizagem. compreensão por parte dos estudantes. Como afirma Santaella (2012) aprender a ler imagens é um desafio que se faz presente, mas a produção das mesmas também o é.

Dentre as diversas possibilidades, Salaverría (2014, p.33) considera o texto como a estrutura principal para peças informativas multimídia. Segundo o autor "o texto atua como elemento de contextualização e de documentação por excelência; informa o utilizador sobre os aspectos essenciais da informação que este tem diante de si". O autor considera ainda que o texto consiste no formato comunicativo mais racional e interpretativo dentre as demais opções. Esta é uma conexão oportuna ao considerar o AVA visto que o ambiente conta com a informação e conteúdo didático ainda bastante baseado no formato textual, talvez não pela facilidade ou comodismo, mas sim por não se ter muito desenvolvidas formas mais visuais e animadas para apresentar um conhecimento pedagógico.

Por fim, falar em características como tactibilidade e plasticidade podem não fazer parte do universo de um AVA se visto sob a perspectiva do acesso via computadores desktop ou notebooks, entretanto, diante o perfil de estudantes, cada vez mais o acesso via smartphone se faz presente abrindo assim as possibilidades de interação e levantando a necessidade de um repensar da oferta dos conteúdos. A ubiquidade é uma das características apresentadas por Canavilhas e cada vez mais, é um alvo de estudo visto o desenvolvimento tecnológico que temos à disposição.

Entende-se que o ambiente virtual de aprendizagem observado neste estudo, carece da diversidade no uso das mídias para então poder promover formas mais rápidas e eficientes no acesso aos conteúdos, na oferta de uma plataforma que facilite a personalização da aprendizagem e que caminhe em direção da ubiquidade, uma característica que demanda possibilidades técnicas especificas, principalmente quando se fala em dispositivos móveis.

\section{BIBLIOGRAFIA}

ARAUJO Jr., Carlos Fernando; MARQUESI, Sueli Cristina. Atividades em ambientes virtuais de aprendizagem: parâmetros de qualidade. In: LITTO, Fredric Michael; FORMIGA, Manuel Marcos Maciel. Educação a Distância : o estado da arte. São Paulo : Pearson Education do Brasil, 2009. pp. 358-368.

\section{CANAVILHAS, João. A reportagem paralaxe} como marca de diferenciação da Web. In Paula Requeijo Rey y Carmen Gaona Pisonero, Contenidos innovadores en la Universidad Actual, pp. 119-129. Madrid: McGraw-Hill Education 2014.

\section{Censo EAD.BR: Relatório Analítico da}

Aprendizagem a Distância no Brasil $2014=$ Censo EAD.BR: Analytic Report of Distance Learning in Brazil/[traduzido por Maria Thereza Moss de Abreu]. Disponível em < http://www.abed.org.br/censoead2014/CensoEAD2 014_portugues.pdf >. Acesso em: 24 ago. 2016. Curitiba: Ibpex, 2015.

ILLERA, José Luiz Rodríguez. Os conteúdos em ambientes virtuais: organização, códigos e formatos de apresentação. In: COLL, Cesar; MONEREO, Carles. Psicologia da Educação Virtual: aprender e ensinar com as tecnologias da informação e Comunicação. Porto Alegre : Artmed, 2010. pp.136-154.

JOHNSON, L., ADAMS BECKER, S., CUMMINS, M., ESTRADA, V., FREEMAN, A., and HALL, C. (2016). NMC Horizon Report: 2016 Higher Education Edition. Austin, Texas: The New Media Consortium.

MANOVICH, Lev. The language of new media. The MIT press Cambridge. London: 2001.

\section{MARTINO, Luís Mauro Sá. Teoria das Mídias \\ Digitais: linguagens, ambientes e redes. Rio de Janeiro : Vozes, 2015. pp. 211-220.}

NUNES, Ivônio Barros. A história da EAD no mundo. In: LITTO, Fredric Michael; FORMIGA, Manuel Marcos Marciel. Educação a distância: estado da arte. São Paulo : Pearson Education do Brasil, 2009. pp.2-8. 


\section{$16^{\circ}$}

ERGODESIGN USIHC CINAHPA $16^{\circ}$ Ergodesign - Congresso Internacional de Ergonomia e Usabilidade de Interfaces Humano Tecnológica: Produto, Informações Ambientes Construídos e Transporte

$16^{\circ}$ USIHC - Congresso Internacional de Ergonomia e Usabilidade de Interfaces Humano Computador

CINAHPA | 2017 - Congresso Internacional de Ambientes Hipermídia para Aprendizagem.

HARASIM, Linda; TELES, Lucio; TUROFF, Murray; HILTZ, Starr Roxanne. Redes de aprendizagem: um guia para ensino e aprendizagem on-line. São Paulo : Senac São Paulo, 2005.

MONEREO, Carles; POZO, Juan Ignácio. O aluno em ambientes virtuais: condições, perfil e competências. In: In: COLL, Cesar; MONEREO, Carles. Psicologia da Educação Virtual: aprender e ensinar com as tecnologias da informação e Comunicação. Porto Alegre : Artmed, 2010. pp.136-154.

PETERS, Otto. Didática no ensino a distância: experiências e estágio da discussão numa visão internacional. São Leopoldo, RS : Unisinos, 2001.

A educação a distância em transição. São Leopoldo, RS : Unisinos, 2003.

SALAVERRÍA, Ramón. Multimedialidade: informar para cinco sentidos. In: CANAVILHAS, João. Webjornalismo: 7 características que marcam a diferença. Livros LabCom : 2014.

SANTAELLA, Lúcia. Como eu ensino: leitura de imagens. Ed. Digital. São Paulo : Melhoramentos, 2012.

ZAWACKI-RICHTER, Olaf; ANDERSON, Terry. Educação a Distância Online: construindo uma agenda de pesquisa. $1^{a}$ ed. São Paulo: Artesanato Educacional, 2015. pp. 221-241. 